\title{
Anti-Herpetic Activity of Callissia fragrans and Simmondsia chinensis Leaf Extracts In Vitro
}

\author{
Ludmila Yarmolinsky ${ }^{1}$, Michele Zaccai ${ }^{2}$, Shimon Ben-Shabat ${ }^{3}$ and Mahmoud Huleihel ${ }^{*}, 1$
}

\author{
${ }^{I}$ Department of Virology and Developmenral Genetics, Faculty of Health Sciences, ${ }^{2}$ Department of Life Sciences and \\ Biotechnology Engineering and ${ }^{3}$ Department of Pharmacology, Faculty of Health Sciences, Ben-Gurion University of \\ the Negev, Beer-Sheva, Israel
}

\begin{abstract}
The antiviral activity of Callissia fragrans and Simnondsia chinensis aquatic and ethanol leaf extracts, as well as purified fractions from these extracts was studied against herpetic viruses in vitro. Ethanol extract of $C$. fragrans effectively inhibited the infection of Vero cells by HSV-1, HSV-2 in vitro, while its aquatic extract inhibited only VZV. Although $S$. chinensis leaf extract strongly inhibited all studied viruses, the selectivity index of this extract was very low, due to its high toxicity. However, the majority of its fractions showed low toxicity and higher antiviral activity and therefore very high SI. Strong interactions between virus and extracts were found.
\end{abstract}

Keywords: HSV-1, HSV-2, VZV, crude extract, fraction, Callissia fragrans, Simnondsia chinensis.

\section{INTRODUCTION}

Although Inch plant [Callissia fragrans (Lindl.) Woodson] and Jojoba (Simmondsia chinensis) have a rich folkloric reputation as antiviral and antimicrobial plants, to the best of our knowledge, no previous scientific reports about their antiviral properties are available.

C. fragrans is a herbaceous plant with small white fragrant flowers and waxy leaves growing wild in Mexico. It has been cultivated as indoor ornamental plants in many countries for 100 years. Lately, there is an increasing interest in its medicinal properties in Eastern Europe. Its leaves are used for treatment of various skin diseases, burns and join disorders. C. fragrans leaves contain biologically active flavonoids, neutral glycol-and phospholipids and their fattyacid compositions [1]. The medicinal properties of $C$. fragrans have not been studied yet.

S. chinensis is an arid perennial shrub indigenous to Arizona, California and Northwestern Mexico. It is also grown in Australia, Brazil, Argentina and some Middle East countries. Its flowers are small, greenish-yellow, with 5-6 sepals and no petals. It is grown in many countries for liquid wax, commonly mistaken for jojoba oil, extracted from its seeds. This liquid wax was used in folk remedies for renal colic, sunburn, chaffed skin, hair loss, headache, wounds, sore throat and as cosmetics [2]. The anti-inflammatory and antimicrobial properties of $S$. chinensis liquid wax have also been previously reported $[3,4]$. Leaves of $S$. chinensis are used in folk medicine for the treatment of various skin diseases.

The chemical content of $S$. chinensis leaves is not well known because most of the studies focused on the chemical

*Address correspondence to this author at the Department of Virology and Developmental Genetics, Faculty of Health Science, Ben-Gurion University of the Negev, Beer-Sheva 84105, Israel; Tel: 08-6479867; Fax: 08-6479867;

E-mails:mahmoudh@bgumail.bgu.ac.il,mahmoudh@bgu.ac.il composition of its seeds which contain high tannins concentration [5].

Although acyclovir (ACV) and other nucleoside derivatives have been approved for therapeutic use against various members of the herpes viruses [6], the search for new effective anti-herpetic drugs is very important due to the following reasons: (a) development of anti-ACV resistant herpes viruses mutants [7], (b) side effects, such as nausea, vomiting and headache, rash and diarrhea, associated with the available drugs and (c) ACV is not highly effective in recurrent virus attacks [8].

In the present study we investigated the antiviral activity of both ethanol and aquatic leaf extracts of $C$. fragrans and $S$. chinensis and their purified fractions on various members of herpes family viruses; herpes simplex viruses type 1 and 2 (HSV-1, HSV-2) and varicella zoster virus (VZV), in vitro.

\section{MATERIALS AND METHODOLOGY}

\subsection{Materials}

C. fragrans and S. chinensis plants were obtained from nurseries and grown in a controlled greenhouse at the Ben Gurion University, Beer-Sheva, Israel.

ACV [9-(2-hydroxyethoxymethyl) guanosine, Sigma] was used as a positive control drug.

\subsection{Preparation of Ethanol and Aquatic Leaf Extracts and Separation of Extracts}

Ethanol and aquatic extracts were prepared from leaves of $C$. fragrans and S. chinensis. Plant tissues were crushed, incubated at room temperature for 48 hours in appropriate solvent, centrifuged at $2000 \mathrm{rpm}$ for $10 \mathrm{~min}$ and the supernatant was evaporated by lyophilizer. The pellet was dissolved in minimal amount of $95 \%$ ethanol $(0.5 \mathrm{ml})$ or water and diluted with water to final concentration of $10 \mathrm{mg} / \mathrm{ml}$. The extracts were sterilized by filtration and diluted with medium containing $2 \%$ Newborn calf serum (NBCS) to the appropriate concentrations. 
Extracts were separated into different fractions using reverse phase column with rising methanol gradient: $0 \%$, $20 \%, 40 \%, 60 \%, 80 \%$ and $100 \%$ (RP-C18 sepack).

\subsection{Cells and Viruses}

African green monkey kidney (Vero) cells were purchased from the American Type Culture Collection (ATCC), Rockville, MD, USA. Cells were grown in Dulbecco's modified Eagle's medium (DMEM) containing $10 \%$ fetal calf serum (FCS), $1 \%$ glutamine, $50 \mathrm{U} / \mathrm{ml}$ penicillin, $50 \mu \mathrm{g} / \mathrm{ml}$ streptomycin and incubated at $37^{\circ} \mathrm{C}$ in a humidified air containing 5\% CO $\mathrm{CO}_{2}$ HSV-1, HSV-2 and VZV were propagated in Vero cells and their concentration was estimated by a standard plaque assay [9].

\subsection{Cytotoxicity Examination}

Vero cells were treated with various concentrations of leaf extracts and the toxicity of the extracts was tested by three different methods:

1. Direct count The cells were counted by Neubauer hemacytometer indicating their replication rate.

2. Morphological changes were observed daily by optical inverted microscope.

3. MTT assay was performed as previously described [10].

\subsection{Antiviral Activity Examination}

The antiviral activity of the tested plant extracts and their fractions was evaluated by plaque assay and cytopathic effect (CPE) development [9].

Table 1. Toxicity of Leaf Extracts at Different Concentrations
In order to elucidate the antiviral mechanism of action of the tested extracts, the cells were treated with the appropriate doses of the extract for different periods of time at/ and or after infection with virus as follow:

a. Treatment only at the time of infection- The appropriate dose of the extract was added to the cells at the time of infection. At the end of $2 \mathrm{~h}$ infection the medium containing the extract was removed and replaced with fresh medium without extract up to the end of the experiment.

b. Treatment at the time and after infection- The appropriate dose of the extract was added to the cells at the time of infection. At the end of $2 \mathrm{~h}$ infection the medium containing the extract was removed and replaced with fresh medium containing the extract up to the end of the experiment.

c. Treatment only at the end of infection- The cells were infected with the virus without treatment with the extract. At the end of $2 \mathrm{~h}$ infection the medium was removed and replaced with fresh medium containing the appropriate dose of the extract up to the end of the experiment.

For examining possible interactions between the examined extracts and the cells, Vero cells were incubated in a medium containing the appropriate dose of the extract at $37^{\circ} \mathrm{C}$ for $2 \mathrm{~h}$, washed 3 times with saline and infected with the virus without further treatment with the leaf extract. For elucidating possible direct effect of the tested extracts on the infectivity of the virus particles, the extracts were incubated with the virus at $4^{\circ} \mathrm{C}$ for different periods of time $(15,30$ and 45 minutes). Then these mixtures were diluted with fresh

\begin{tabular}{|c|c|c|c|c|}
\hline Viability $^{1}$ (\% of Control) & Cell Number ${ }^{2}$ (\% of Control) & Concentration $(\mu \mathrm{g} / \mathrm{ml})$ & Extract Type & Plant \\
\hline $99.9 \pm 3.09$ & $102.5 \pm 0.36$ & 10 & \multirow{3}{*}{ Ethanol } & \multirow{7}{*}{ C. fragrans } \\
\hline $97.1 \pm 3.07$ & $100.6 \pm 0.46$ & 500 & & \\
\hline $72.6 \pm 4.90$ & $65.3 \pm 3.81$ & 1000 & & \\
\hline $101.8 \pm 3.55$ & $101.1 \pm 2.45$ & 10 & \multirow{4}{*}{ Aquatic } & \\
\hline $101.5 \pm 3.48$ & $101.1 \pm 1.78$ & 100 & & \\
\hline $100.7 \pm 3.45$ & $100.2 \pm 2.36$ & 500 & & \\
\hline $100.8 \pm 2.78$ & $100.7 \pm 2.61$ & 1000 & & \\
\hline $33.6 \pm 1.27$ & $36.9 \pm 1.27$ & 500 & Ethanol & \multirow{4}{*}{ S. chinensis } \\
\hline $102.6 \pm 4.56$ & $101.1 \pm 2.15$ & 10 & \multirow{3}{*}{ Aquatic } & \\
\hline $101.2 \pm 3.78$ & $100.5 \pm 2.98$ & 50 & & \\
\hline $43.6 \pm 3.45$ & $46.8 \pm 2.17$ & 100 & & \\
\hline
\end{tabular}

${ }^{1}$ Average of 3 cultures \pm SD. Viability of cells was evaluated by MTT assay after 4 days of treatment with the plant extract. ${ }^{2}$ Average of 3 cultures $\pm \mathrm{SD}$, after 4 days of treatment. 
medium and cell monolayers were infected with the diluted mixture.

The selectivity index (SI) was determined as $\mathrm{CC}_{50} / \mathrm{EC}_{50}$, where $\mathrm{CC}_{50}$ is the concentration found to cause $50 \%$ toxicity and $\mathrm{EC}_{50}$ is concentration found to provide $50 \%$ prevention of plaque forming units (PFU).

\subsection{Statistical Analysis}

All data were analyzed using Statistica for Windows software (StatSoft, Inc., Tulsa, Oklahoma), and $\mathrm{P}<0.05$ was chosen as the minimal acceptable level of significance.

\section{RESULTS}

\subsection{Cytotoxicity Examination}

Vero cells were treated with the extracts at different concentrations $(1-1500 \mu \mathrm{g} / \mathrm{ml})$ for 4 days. Our results (Table 1) show that both ethanol and aquatic extracts of $C$. fragrans didn't show any toxicity at concentrations $\leq 500 \mu \mathrm{g} / \mathrm{ml}$, however, the aquatic extracts were less toxic than ethanol extracts. Both ethanol and aquatic of $S$. chinensis leaf extracts had a high cytotoxicity.

\subsection{Antiviral Activity Examination}

Vero cell monolayers were treated with increasing extract concentrations at the time of infection with 0.1 m.o.i. of HSV-1, HSV-2 or VZV. The treatment was terminated immediately post-infection (p.i) and the antiviral activity was evaluated by plaque assay.

Fig. (1) demonstrates that the best results were obtained with ethanol extract of $C$. fragrans which showed the highest SI against HSV-1, HSV-2 and HSV-2 mutant (resistant to ACV), while it was ineffective against VZV. The ethanol extract of $S$. chinensis was not effective against all tested viruses due to its high toxicity. Therefore, it was not included in the further experiments with the extracts. Although SI of all used extracts were lower than that of ACV (Table 3), these extracts nevertheless inhibited ACVresistant HSV-2 mutant (Fig. 1).

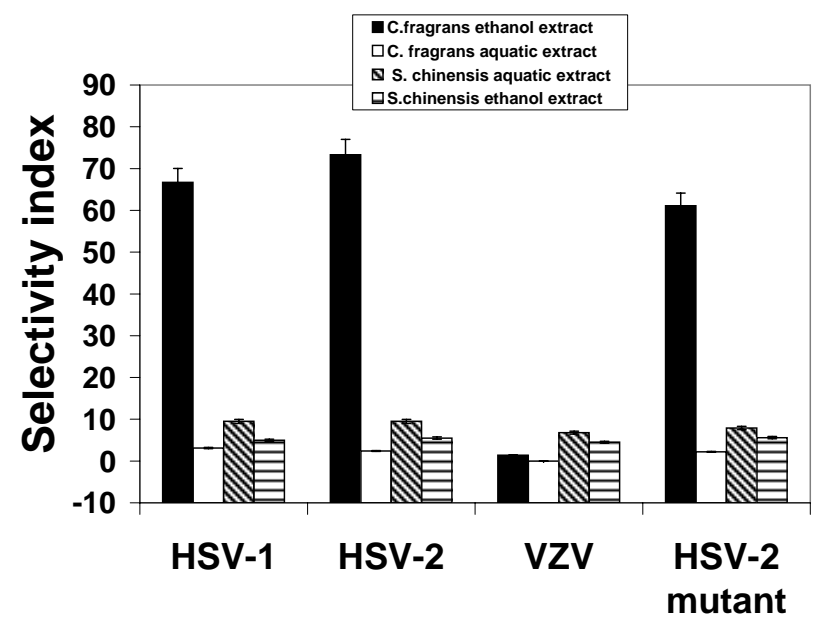

Fig. (1). Selectivity index (SI) of plant extracts against HSV-1, HSV-2, VZV and HSV-2 mutant (resistant to ACV). SI was determined as $\mathrm{CC}_{50} / \mathrm{EC}_{50}$. Values are means $\pm \mathrm{SD}(\mathrm{n}=5)$.

\subsection{Mechanism of Action}

Vero cells were infected with 0.1 m.o.i. of the examined herpes viruses and treated with $100 \mu \mathrm{g} / \mathrm{ml}$ of $C$. fragrans leaf extracts or $50 \mu \mathrm{g} / \mathrm{ml}$ of $S$. chinesis aquatic extract for various periods of time before, at, or after infection. When the cells were treated with the extracts only at the time of infection or both at the time and post-infection, the inhibition of all examined viruses was the highest (Table 2). It seems that pre-incubation of the cells with the extracts (without further treatment) had no significant effect on the development of infection induced by all examined viruses $(p>0.1)$. However, treatment of the infected cells only p. i. caused partial inhibition of the viral infection (Table 2).

Plant extracts are thought to exert their inhibitory action at a very early stage in the viral infection cycle i.e. virus adsorption onto and/or penetration into the host cell.

In order to examine possible interactions between viral particles and leaf extracts, the tested viruses were preincubated with the extracts, then these mixtures were diluted

Table 2. Effect of Time of Leaf Extract Addition on Herpes Viruses Infection

\begin{tabular}{|c|c|c|c|c|c|}
\hline \multicolumn{4}{|c|}{ PFU (\% of Control) } & \multirow{2}{*}{$\begin{array}{c}\text { Virus } \\
(0.1 \text { m.o.i. })\end{array}$} & \multirow{2}{*}{ Leaf Extract } \\
\hline During Infection and After Infection & $\begin{array}{c}\text { Only After } \\
\text { Infection }\end{array}$ & $\begin{array}{l}\text { Only During } \\
\text { Infection }\end{array}$ & $\begin{array}{l}\text { Only Before } \\
\text { Infection }\end{array}$ & & \\
\hline $90.2 \pm 2.45$ & $99.4 \pm 3.22$ & $97.3 \pm 2.67$ & $100.1 \pm 1.36$ & HSV-1 & \multirow{3}{*}{ C. fragrans (aquatic extract) } \\
\hline $92.0 \pm 1.65$ & $99.6 \pm 2.78$ & $98.0 \pm 3.07$ & $99.6 \pm 2.24$ & HSV-2 & \\
\hline $1.0 \pm 0.32$ & $16.52 \pm 0.87$ & $1.4 \pm 0.75$ & $98.7 \pm 2.87$ & VZV & \\
\hline $20.0 \pm 0.8$ & $65.22 \pm 3.14$ & $.9 \pm 1.227$ & $100 \pm 1.39$ & HSV-1 & \multirow{3}{*}{ C. fragrans (ethanol extract) } \\
\hline $12.6 \pm 3.12$ & $59.25 \pm 2.56$ & $23.5 \pm 2.25$ & $101.1 \pm 2.14$ & HSV-2 & \\
\hline $76.3 \pm 4.53$ & $98.25 \pm 1.94$ & $84.2 \pm 2.89$ & $100.2 \pm 1.52$ & VZV & \\
\hline $3.4 \pm 0.98$ & $42.85 \pm 2.5$ & $11.4 \pm 3.2$ & $3.6 \pm 2.15$ & HSV-1 & \multirow{3}{*}{ S. chinensis (aquatic extract) } \\
\hline $2.1 \pm 0.65$ & $38.25 \pm 2.14$ & $9.6 \pm 2.07$ & $94.1 \pm 1.89$ & HSV-2 & \\
\hline $7.2 \pm 1.98$ & $48.56 \pm 4.02$ & $16.3 \pm 1.58$ & $95.3 \pm 3.08$ & VZV & \\
\hline
\end{tabular}

Vero cell monolayers were treated with $100 \mu \mathrm{g} / \mathrm{ml}$ of the $C$. fragrans extracts and $50 \mu \mathrm{g} / \mathrm{ml}$ of the $S$. chinensis aquatic extract before, at or after infection with $0.1 \mathrm{~m} .0 .1$. of $\mathrm{HSV}-1$, HSV-2 or VZV. Antiviral activity was evaluated by plaque assay. Values are presented as means \pm SD $(n=5)$. 
with a fresh medium to antivirally inactive concentrations of the extract. The diluted mixtures were used for infecting Vero cell monolayers. Our results showed considerable inhibition of plaque formation by the highly diluted extracts mixtures (Fig. 2). Most significant inhibition of the tested viruses was obtained after 30-45 minutes of incubation with the different extracts (Fig. 2).

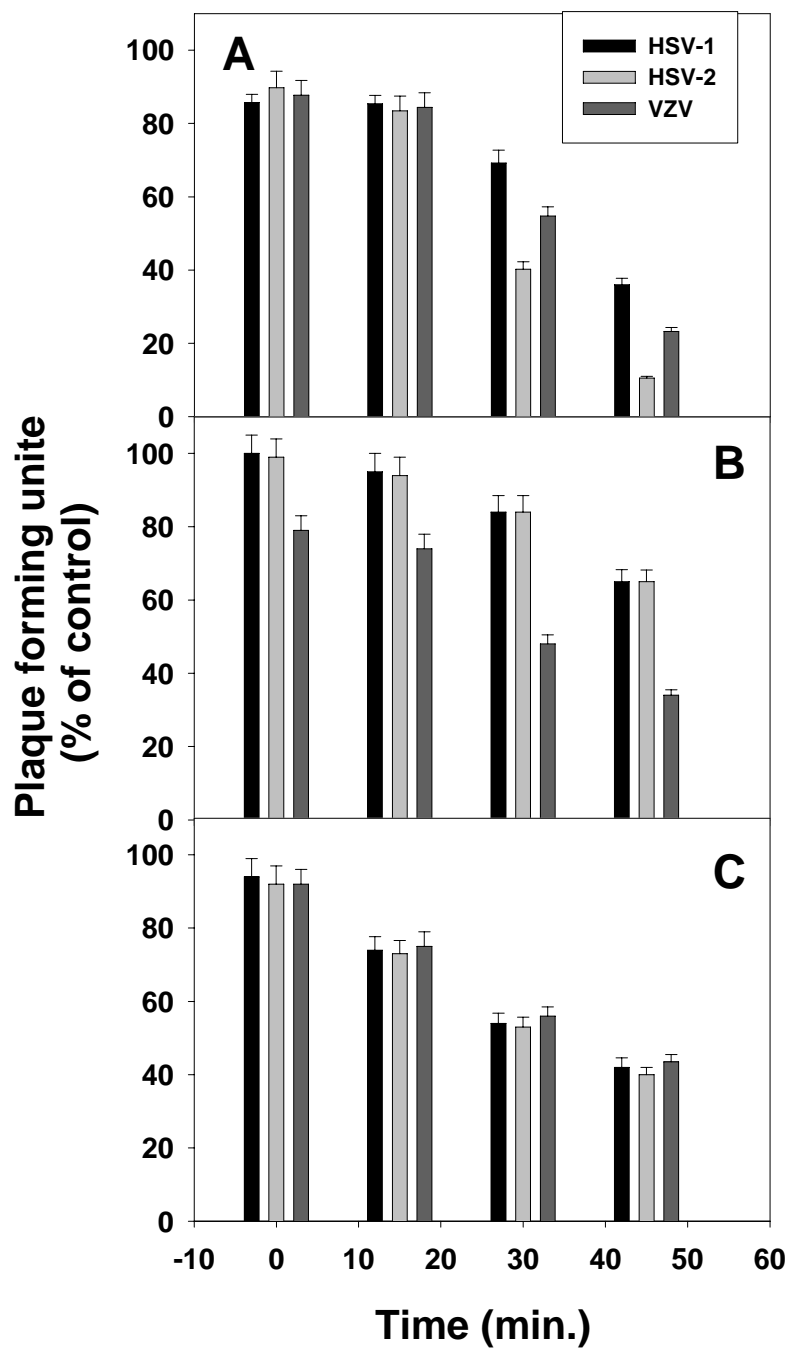

Fig. (2). Effect of pre-incubation of leaf extracts with HSV-1, HSV2 and VZV on virus infectivity. (A) $1000 \mu \mathrm{g} / \mathrm{ml}$ of C. fragrans ethanol leaf extract, (B) $1000 \mu \mathrm{g} / \mathrm{ml}$ of C. fragrans aquatic leaf extracts and (C) $100 \mu \mathrm{g} / \mathrm{ml}$ of $S$. chinensis aquatic leaf extracts were incubated with the infecting virus $(5 \mathrm{~m}$.o.i. $)$ at $4{ }^{\circ} \mathrm{C}$ for different periods of time (15, 30 and 45 minutes). Every mixture was diluted $10^{4}$ times with fresh medium and the cells were infected with the diluted mixture. PFU were evaluated by the standard plaque assay and presented as means $\pm \mathrm{SD}(\mathrm{n}=5)$.

\subsection{Effect of Extract Removal on CPE Development}

Vero cells were infected with 0.5 m.o.i. of HSV-1 and treated with $500 \mu \mathrm{g} / \mathrm{ml}$ ethanol extract of $C$. fragrans immediately post infection. At different periods of time p.i. $(1,3,10$ days $)$ the treatment with the extract was terminated. It can be seen that continuous treatment almost prevented the CPE development of all examined viruses (about 95\% prevention) during the period of experiment (Fig. 3). However, when the leaf extract was removed even at 10 days p.i., a moderate increase in CPE development was observed (Fig. 3). Similar results were obtained with other plant extracts and other viruses (data not shown). The continuous presence of the leaf extracts in the cell culture medium is apparently essential for continuous protection of Vero cells against viral CPE development.

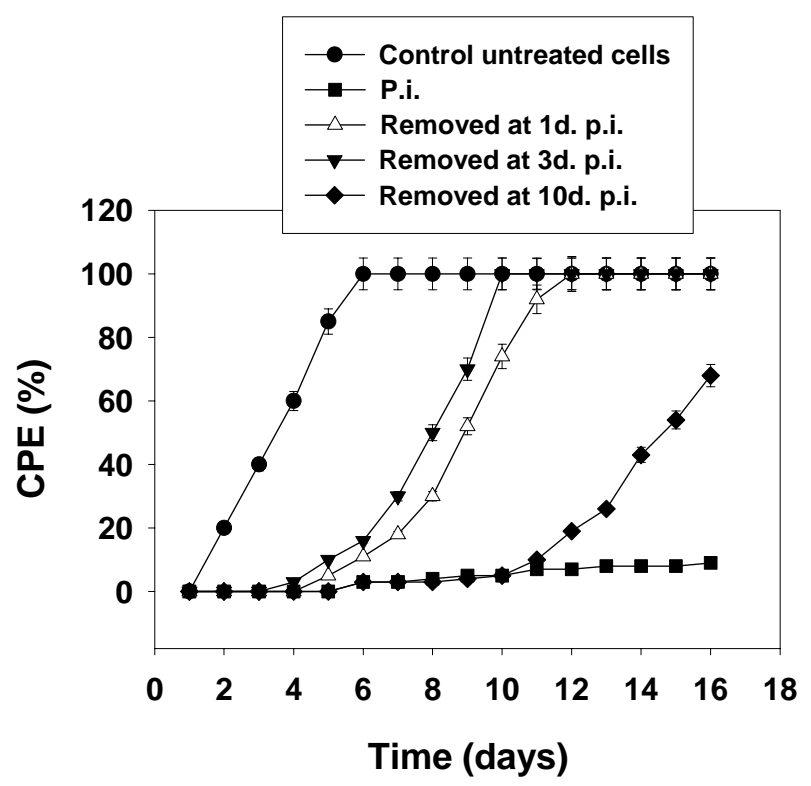

Fig. (3). Effect of leaf extracts removal on the development of herpes viruses cytophatic effect (CPE). Vero cells were infected with 0.05 m.o.i. of HSV-1 and treated with $500 \mu \mathrm{g} / \mathrm{ml}$ of $C$. fragrans ethanol leaf extract at the end of infection. The treatment was terminated at 1, 3 or 10 days p. i. CPE development was evaluated every $24 \mathrm{~h}$ by inverted microscopy and expressed as the percentage of damaged cells in the culture. Data are means \pm SD of three independent experiments.

3.5. Antiviral Activity of Fractions of $C$. fragrans and $S$. chinensi Extracts

Cytotoxicity and antiviral activity of several fractions from the plant extracts were examined. The obtained results (Table 3) showed that for $C$. fragrans, fraction $60 \%-\mathrm{MeOH}$ of the ethanol extract strongly inhibited HSV-1 and HSV-2 but only slightly VZV, whereas fraction $20 \%-\mathrm{MeOH}$ of the aquatic extract significantly inhibited all tested viruses. All fractions of both ethanol and aquatic extracts of S. chinensis showed relatively high SI but the $60 \%-\mathrm{MeOH}$ fraction of the ethanol extract had the highest SI (Table 4).

\section{DISCUSSION}

The extracts tested in this study may therefore provide a potential source of effective anti-herpetic compounds which seem less toxic than ACV and effective against HSV mutants resistant to $\mathrm{ACV}$, whose prevalence has increased to $7 \%$ for last 20 years [11].

In fact, the antiviral activity of the various examined extracts against the different viruses was significantly lower than that of ACV, as presented by their SI values (Fig. 1 and Table 4). 
Our results suggest, in agreement with previous findings $[12,13]$, that the examined plant extracts exert their antiherpetic effect mainly by direct interaction with the virus particles and by blocking the virus access to the host cells. The significant inhibition of the tested herpes viruses as a result of direct effect of the extracts (Fig. 2) suggests strong interactions between the extract and the herpetic viruses. This effect could be caused either by a strong or maybe irreversible interaction between the virus and the extract, the effect being maintained after several serial dilutions, or by a direct inactivation of the virus. Our results didn't show any inhibition of the viral infection in plant-extract pretreated cell cultures (Table 2). This could be explained by either a weak and reversible interaction or completely missinteraction between the extract and the cell membrane. It is important also to mention that treatment of the infected cells only p.i. with the extracts caused partial inhibition of the viral infection (Table 2). This inhibition could be a result of preventing re-infections with the newly produced viruses by the extracts. All the above mentioned results do not exclude the possibility of inhibitory effect of these extracts on additional steps during the replication cycle of the examined viruses. Our ongoing study is examining also these possibilities.

However, separation of these extracts into different fractions dramatically improved their SI mainly due to the decreased cytotoxicity of these fractions compared to the crude extracts (Tables 3 and 4). The obtained SI of all tested crude extracts and fractions for HSV-1 were significantly higher than those mentioned in the current literature $[14,15]$.
It is worthwhile highlighting the impressive increase in SI values of $S$. chinensi fractions compared to their crude extracts. Best SI values were obtained with fraction $60 \%$ $\mathrm{MeOH}$ of the different extracts. It seems according our experience that this fraction is rich with polyphenols. In addition, it can be seen from the results presented in Table $\mathbf{4}$ that most of $S$. chinensis fractions show antiviral activity, which might indicate for the presence of various components in the extract that have antiviral activity. As we know each fraction still composes different substances.

Additional investigation is required for further isolation and identification of the plant antiviral agents from effective fractions.

\section{CONCLUSION}

1. The C. fragrans ethanol extract effectively inhibited the infection of Vero cells by HSV-1, HSV-2 in vitro, while its aquatic extract inhibited only VZV.

2. S. chinensis leaf extracts strongly inhibited all studied viruses, but their high cytotoxicity led to lower SI values.

3. In general, purified fractions of the tested plants had low cytotoxicity and very high SI.

4. The highest antiviral activity of the extracts against all tested viruses was obtained when the cells were treated with the extracts at the time and post infection.

5. Strong interaction between the virus and the extracts is suggested.

Table 3. Antiviral Activity of Crude Extracts and Fractions of $C$. fragrans Against Herpetic Viruses

\begin{tabular}{|c|c|c|c|c|c|c|c|}
\hline \multirow{2}{*}{ Extract/Fraction } & \multirow{2}{*}{$\mathrm{CC}_{50}(\mu \mathrm{g} / \mathrm{ml})$} & \multicolumn{2}{|c|}{ HSV-1 } & \multicolumn{2}{|c|}{ HSV-2 } & \multicolumn{2}{|c|}{$\mathrm{VZV}$} \\
\hline & & $\mathrm{EC}_{50}(\mu \mathrm{g} / \mathrm{ml})$ & SI & $\mathrm{EC}_{50}(\mu \mathrm{g} / \mathrm{ml})$ & SI & $\mathrm{EC}_{50}(\mu \mathrm{g} / \mathrm{ml})$ & SI \\
\hline \multicolumn{8}{|c|}{ C. fragrans, Ethanol Extract } \\
\hline Crude extract & 1100 & 16.5 & 66.6 & 15 & 73.3 & 800 & 1.4 \\
\hline $0 \%-\mathrm{MeOH}$ & $>1000$ & Inactive & - & Inactive & - & Inactive & - \\
\hline $20 \%-\mathrm{MeOH}$ & $>1000$ & 40 & $>25$ & 35 & $>28.6$ & 21 & $>47.6$ \\
\hline $40 \%-\mathrm{MeOH}$ & $>1000$ & 30 & $>33.3$ & 28 & $>35.7$ & 40 & $>25$ \\
\hline $60 \%-\mathrm{MeOH}$ & $>1000$ & 8 & $>125$ & 5 & $>200$ & 32 & $>31.3$ \\
\hline $80 \%-\mathrm{MeOH}$ & $>1000$ & Inactive & - & Inactive & - & 84 & $>11.9$ \\
\hline $100 \%-\mathrm{MeOH}$ & $>1000$ & 35 & $>28.6$ & 32 & $>31.2$ & 100 & $>10$ \\
\hline \multicolumn{8}{|c|}{ C. fragrans, Aquatic Extract } \\
\hline Crude extract & 1550 & 500 & 3.1 & 650 & 2.4 & 17 & 91.2 \\
\hline $0 \%-\mathrm{MeOH}$ & $>1000$ & Inactive & - & Inactive & - & Inactive & - \\
\hline $20 \%-\mathrm{MeOH}$ & $>1000$ & 2 & $>500$ & 5 & $>200$ & 7 & $>142.8$ \\
\hline $40 \%-\mathrm{MeOH}$ & $>1000$ & 15 & $>66.7$ & 20 & $>50$ & 5 & $>200$ \\
\hline $60 \%-\mathrm{MeOH}$ & $>1000$ & 40 & $>25$ & 45 & $>22.2$ & 70 & $>14.3$ \\
\hline $80 \%-\mathrm{MeOH}$ & $>1000$ & Inactive & - & Inactive & - & 20 & $>50$ \\
\hline $100 \%-\mathrm{MeOH}$ & $>1000$ & 9.5 & $>105.3$ & 12 & $>83.3$ & Inactive & - \\
\hline $\mathrm{ACV}$ & 70 & 0.1 & 700 & 0.25 & 280 & 0.15 & 466.7 \\
\hline
\end{tabular}

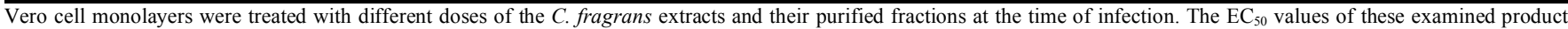
were determined and the SI values were calculated. Antiviral activity was evaluated by plaque assay. 
Table 4. Antiviral Activity of Crude Extracts and Fractions of $S$. chinensis and ACV Against Herpetic Viruses

\begin{tabular}{|c|c|c|c|c|c|c|c|}
\hline \multirow{2}{*}{ Material } & \multirow{2}{*}{$\mathrm{CC}_{50}(\mu \mathrm{g} / \mathrm{ml})$} & \multicolumn{2}{|c|}{ HSV-1 } & \multicolumn{2}{|c|}{ HSV-2 } & \multicolumn{2}{|c|}{ VZV } \\
\hline & & $\mathrm{EC}_{50}(\mu \mathrm{g} / \mathrm{ml})$ & SI & $\mathrm{EC}_{50}(\mu \mathrm{g} / \mathrm{ml})$ & SI & $\mathrm{EC}_{50}(\mu \mathrm{g} / \mathrm{ml})$ & SI \\
\hline \multicolumn{8}{|c|}{ S. chinensis, Ethanol Extract } \\
\hline Crude extract & 250 & 50 & 5 & 45 & 5.5 & 55 & 4.5 \\
\hline $0 \%-\mathrm{MeOH}$ & 500 & 9.5 & 52.6 & 8 & 62.5 & 5 & 100 \\
\hline $20 \%-\mathrm{MeOH}$ & 450 & 8 & 56.2 & 7.5 & 62.3 & 4 & 112.5 \\
\hline $40 \%-\mathrm{MeOH}$ & 400 & 5.5 & 72.72 & 5 & 80 & 4.5 & 88.9 \\
\hline $60 \%-\mathrm{MeOH}$ & $>1000$ & 9 & $>111.1$ & 9 & $>111.1$ & 4 & $>250$ \\
\hline $80 \%-\mathrm{MeOH}$ & 70 & 4.5 & 15.6 & 4 & 17.5 & 8.5 & 8.2 \\
\hline $100 \%-\mathrm{MeOH}$ & 60 & 6 & 10 & 5.5 & 10.9 & 6.5 & 9.2 \\
\hline \multicolumn{8}{|c|}{ S. chinensis, Aquatic Extract } \\
\hline Crude extract & 95 & 10 & 9.5 & 10 & 9.5 & 14 & 6.78 \\
\hline $0 \%-\mathrm{MeOH}$ & 50 & 3 & 16.7 & 3.5 & 14.3 & 8 & 6.2 \\
\hline $20 \%-\mathrm{MeOH}$ & 400 & 5.5 & 72.7 & 5.5 & 72.7 & 9 & 44.4 \\
\hline $40 \%-\mathrm{MeOH}$ & 500 & 2.5 & 200 & 2.5 & 200 & 8.5 & 58.8 \\
\hline $60 \%-\mathrm{MeOH}$ & 500 & 2.2 & 227.3 & 2.5 & 200 & 3.5 & 142.9 \\
\hline $80 \%-\mathrm{MeOH}$ & $>1000$ & 7 & $>142.8$ & 7.5 & $>62.3$ & 3 & $>333.3$ \\
\hline $100 \%-\mathrm{MeOH}$ & $>1000$ & 5 & $>200$ & 5 & $>200$ & 2 & $>200$ \\
\hline $\mathrm{ACV}$ & 70 & 0.1 & 700 & 0.25 & 280 & 0.15 & 466.7 \\
\hline
\end{tabular}

Vero cell monolayers were treated with different doses of the S. chinensis extracts and their purified fractions at the time of infection. The $\mathrm{EC}_{50}$ values of these examined products were determined and the SI values were calculated. Antiviral activity was evaluated by plaque assay.

\section{ACKNOWLEDGEMENT}

We thank Prof. Zeev Weisman for his helpful advice and for giving a possibility to use his laboratory equipments.

\section{REFERENCES}

[1] Chernenko TV, Ulchenko NT, Glushenkova AI, Redzhepov D. Chemical investigation of Callisia fragrans. Chem Nat Comp 2007; 3: 253-5.

[2] Mbah CJ. Studies on the lipophilicity of vehicles (or co-vehicles) and botanical oils used in cosmetic products. Pharmazic 2007; 62: 351-3.

[3] Habashy RR, Abdel-Naim AB, Khalifa AE, Al-Azizi MM. Antiflammatory effects of liquid wax in experimental models. Pharm Res 2005; 51: 95-105.

[4] Prijck KD, Peeters E, Nelis HJ. Comparison of solid-phase cytometry and the plate count method for the evaluation of the survival of bacteria in pharmaceutical oils. Lett Appl Microb 2008; 47: $571-3$

[5] Gayol MF, Labuckas DO, Oberti JC, Guzman CA. Chemical characterization of jojoba seeds (Simmondsia Chinensis (link) Schneider), Proceeding from "Banado De Los Pantanos", La Rioja, Argentina. J Argen Chem Soc 2004; 92: 4-6.

[6] Brady RC, Bernstein DI. Treatment of herpes simplex virus infections. Antiviral Res 2004; 61: 73-81.
[7] Field AK, Biron KK. The end of innocence revisited: resistance of herpesviruses to antiviral drugs. Clin Microbiol Rev 1994; 7: 1-13.

[8] Devrim I, Tezer H, Haliloqlu G, Kara A, Secmeer G. Relapsing Herpes simplex virus encephalitis despite high-dose acyclovir therapy: a case report. Turk J Ped 2008; 50: 380-2.

[9] Huleihel M, Ishanu V, Tal J, Arad (Malis) S. Antiviral effect of red microalgal polysaccharides on Herpes simplex and Varicella zoster viruses. J Appl Phycol 2001; 13: 127-34.

[10] Shi Y, Kornovski BS, Savani R, Turley EA. A rapid, multiwell colorimetric assay for chemotaxis. J. Immunol Methods 1993; 164: 149-54.

[11] Stranks KR, Schuurman R, Neinhuis E, et al. Survey of acyclovirresistant herpes simplex virus in the Netherlands: prevalence and characterization. J Clin Virol 2005; 32: 7-18.

[12] Li Y, But PP, Ooi VE. Antiviral activity and mode of action of caffeolquinic acids from Scheffleraheptaphylla (L) Frodin. Antiviral Res 2005; 67: 107-19.

[13] Yarmolinsky L, Zaccai M, Ben-Shabat S, Mills D, Huleihel M. Antiviral activity of ethanol extracts of Ficus binjamina and Lilium candidum in vitro. N Biotechnol 2009; 6: 307-13.

[14] Muller V, Chavez JH, Reginatto FH, et al. Evaluation of antiviral activity of South American plant extracts against Herpes Simplex Virus Type 1 and Rabies Virus. Phytother Res 2007; 21: 970-4.

[15] Alvares AL, Gloria B, Koun V, Martinez PF, Suarez B, Parra F. In vitro anti-herpetic activity of an aqueous extract from the plant Phyllanthus orbicularis. Phytomedicine 2009; 16: 960-6.

(C) Yarmolinsky et al.; Licensee Bentham Open.

This is an open access article licensed under the terms of the Creative Commons Attribution Non-Commercial License (http: //creativecommons.org/licenses/by-nc/ $3.0 /$ ) which permits unrestricted, non-commercial use, distribution and reproduction in any medium, provided the work is properly cited. 